\title{
Research experiences on the reuse of industrial waste for concrete production
}

\author{
Alessandro Abbà ${ }^{1, *}$, Sabrina Sorlini ${ }^{2}$, and Maria Cristina Collivignarelli ${ }^{1}$ \\ ${ }^{1}$ University of Pavia, Department of Civil and Architectural Engineering, via Ferrata 1, 27100 Pavia, \\ Italy \\ ${ }^{2}$ University of Brescia, Department of Civil, Environmental, Architectural Engineering and \\ Mathematics, via Branze 43, 25123 Brescia, Italy
}

\begin{abstract}
The aim of this study was to assess the feasibility of concrete production using different kinds of industrial wastes as "recycled aggregate". The wastes studied in this work were: fly ashes and slags from Electric Arc Furnace (EAF) steel plant; foundry sands produced from foundry dies; slags from lead processing; Waelz slags; solid residues from municipal solid waste incineration (MSWI) plant (with mass-burning kiln and fluidized bed reactor); sludge from industrial wastewater treatment plants. Good compressive strength (similar to natural concrete) was achieved after 28 days of curing by concrete mixtures obtained with the partial replacement (from 7\% to $40 \%$ by weight) of natural aggregates with slags from lead processing, foundry sands, Waelz slags and bottom ashes from MSW incineration. The worst mechanical and leaching behaviours were shown by concrete samples containing EAF fly ashes and sludge from industrial wastewater treatment. For the residues with the best performance, concrete products (kerbs and flat tiles) were casted. Their mechanical and leaching characterization has shown that the reuse of these residues for concrete product is feasible.
\end{abstract}

\section{Introduction}

Concrete is a composite material that consists of different constituents such as binding materials, water, aggregates and admixtures. Among these ingredients, aggregate plays a very crucial role in concrete as it represents about $60-75 \%$ of total concrete volume. The extensive increase of industrialization and urbanization processes progressively increased the exploitation of natural resources for the production of concrete in the construction industry. Concrete has a very important role in the economy development of a country due to its large volume utilization. In the world, it uses approximately 20 billion tons of raw materials (coarse aggregate) each year $[1,2]$.

The use of low impact, renewable and recyclable building materials and the reusability of industrial by-products for construction purposes should be prioritised in the design, construction and management to achieve environmentally sustainable infrastructures [3]. Moreover, according to European [4] and Italian [5] legislation, a growing interest on the

\footnotetext{
*Corresponding author: abba78@unipv.it
} 
possibility of using industrial wastes in concrete was observed, since this allows to: (i) save natural resources as conventional aggregates; (ii) reduce energy consumption due to mining activities; (iii) preserve environment; (iv) avoid the increase of landfill volume.

Many wastes produced by industrial activities can offer interesting characteristics for their potential reuse as construction materials. About this, the residues from metallurgical industry, municipal solid waste incineration (MSWI) and sludge from wastewater treatment plants (WWTPs) could be interesting for reuse in different fields also due to the quantity involved.

As concerns the metallurgical industry, according to the Euroslag Organization, 45.3 million tons of ferrous metallurgy slag was produced in 2010 [6]. The steel slag amount (derived from steel production) is equal to 29.6 and 4.1 million tons in Europe and in Italy, respectively [7]. Moreover, the recycling of Electric Arc Furnace (EAF) dusts produced in the European Union could lead to the generation of nearly 800,000 tons per year of Waelz slag [8]. Furthermore, in Europe, around 18 million tons of foundry sands is left over every year and in many cases big landfills do not have enough capacity to deposit those large amounts of surplus foundry sand [9].

About the municipal solid waste incineration (MSWI) sector, the solid residues produced in Europe can be estimated in 18 and 4 million tons for bottom ash and fly ash, respectively [10].

Finally, as regards the sewage sludge from wastewater treatment plants (WWTPs), the production in Europe will rise to just under 13.0 million tons in 2020 [11]. Actually, especially in Italy, the main routes for sludge disposal and recycling is the agricultural reuse, which could involve critical issues related to heavy metal accumulation and odour emissions [12].

The aim of this work is to evaluate the potential reuse of different industrial wastes as "recycled aggregate" in construction materials and to assess the mechanical and environmental characteristics of concrete containing these residues.

\section{Material and methods}

The wastes studied as aggregate replacement for concrete production are:

- fly ashes from electric arc furnace (EAF) steel plant (Steel FA);

- slags from electric arc furnace (EAF) steel plant (Steel SLAG);

- foundry sands produced from foundry dies (Foundry SAND);

- slags from lead processing (Lead SLAG);

- Waelz slags (Waelz SLAG);

- bottom ashes from MSWI plants with a mass-burning kiln (BA(MSWI-A)) and a fluidized bed reactor (BA(MSWI-B));

- exhausted sands from MSWI fluidized bed reactor (ES(MSWI-B));

- sludge from an industrial WWTP treating wastewater from galvanic industry (WWTP SLUDGE).

Some kinds of solid residues were used after pre-treatments mainly based on crushing and sieving operation in order to obtain a granular distribution suitable for concrete production; as concerns the solid residues from MSWI, iron removal and washing treatments were also applied with the aim to reduce the content of pollutants. The specific processes applied for waste pre-treatments are reported in Table 1.

Moreover, concrete mixtures were casted with the partial replacement of natural aggregate with different amounts of solid residues (see Table 2). For each residue, a reference mixture was casted only with natural aggregates, in order to compare the performance. 
Table 1. Residues analyzed in the work and pre-treatments applied.

\begin{tabular}{|c|c|c|c|}
\hline Residue & Pre-treatment & Residue name & $\begin{array}{c}\text { Granular } \\
\text { distribution } \\
{[\mathrm{mm}]}\end{array}$ \\
\hline Fly ashes from EAF steel slag & - & Steel FA & $0.05-0.125$ \\
\hline \multirow[b]{2}{*}{ Slags from EAF steel plant } & Crushing and sieving & Steel SLAG & $0-31.5$ \\
\hline & $\begin{array}{l}\text { Crushing, sieving and } \\
\text { ageing (for 3-4 } \\
\text { months) }\end{array}$ & Aged Steel SLAG & $0-31.5$ \\
\hline Foundry sands & - & Foundry SAND & $0.125-0.5$ \\
\hline Slags from lead processing & - & Lead SLAG & $0.5-31.5$ \\
\hline \multirow[b]{2}{*}{ Waelz slags } & - & Waelz SLAG & - \\
\hline & Ageing (for 6 months) & $\begin{array}{l}\text { Aged Waelz } \\
\text { SLAG }\end{array}$ & - \\
\hline \multirow{6}{*}{$\begin{array}{l}\text { Bottom ashes from MSWI } \\
\text { mass-burning kiln }\end{array}$} & \multirow{3}{*}{$\begin{array}{l}\text { Sieving and iron } \\
\text { removal }\end{array}$} & \multirow{3}{*}{ BA(MSWI-A) } & $0-10$ \\
\hline & & & $10-20$ \\
\hline & & & $20-30$ \\
\hline & \multirow{3}{*}{$\begin{array}{l}\text { Sieving, iron removal } \\
\text { and washing }\end{array}$} & \multirow{3}{*}{ WBA(MSWI-A) } & $0.063-2$ \\
\hline & & & $2-10$ \\
\hline & & & $2-20$ \\
\hline $\begin{array}{l}\text { Bottom ashes from MSWI } \\
\text { fluidized bed reactor }\end{array}$ & $\begin{array}{l}\text { Sieving and iron } \\
\text { removal }\end{array}$ & BA(MSWI-B) & $0-10$ \\
\hline $\begin{array}{c}\text { Exhausted sands from MSWI } \\
\text { mass-burning kiln }\end{array}$ & 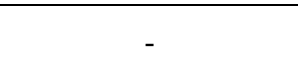 & ES(MSWI-B) & $0-2$ \\
\hline $\begin{array}{c}\text { Sludge from industrial } \\
\text { WWTPs }\end{array}$ & Drying and crushing & WWTP SLUDGE & $0-1$ \\
\hline
\end{tabular}

Table 2. Concrete mixtures mix design

\begin{tabular}{|c|c|c|c|c|}
\hline \multirow{2}{*}{ Type of residue } & \multicolumn{3}{|c|}{ Amount $\left[\mathbf{k g ~ m}^{-3}\right]$} & $\begin{array}{c}\text { Water/ } \\
\text { cement } \\
\text { ratio }\end{array}$ \\
\cline { 2 - 4 } & Residue & $\begin{array}{c}\text { Natural } \\
\text { aggregate }\end{array}$ & Cement (type) & 0.65 \\
\hline Steel FA & 200 & 1800 & $270(32.5 \mathrm{R})$ & 0.43 \\
\hline Aged Steel SLAG & 2580 & - & $380(32.5 \mathrm{R})$ & 0.65 \\
\hline Foundry SAND & 200 & 1800 & $270(32.5 \mathrm{R})$ & 0.65 \\
\hline Lead SLAG & 200 & 1800 & $220-300(32.5 \mathrm{R}-42.5 \mathrm{R})$ & $0.48-0.54$ \\
\hline Waelz SLAG* & $200-600$ & $1330-1730$ & $250-400(32.5 \mathrm{R}-42.5 \mathrm{R})$ & 0.54 \\
\hline Aged Waelz SLAG & $200-400$ & $1530-1730$ & $300(32.5 \mathrm{R})$ & 0.4 \\
\hline BA(MSWI-A) & 400 & 1270 & $300(32.5 \mathrm{R})$ & 0.4 \\
\hline WBA(MSWI-A) & $200-1700$ & $0-1500$ & $300-400(32.5 \mathrm{R}-42.5 \mathrm{R})$ & 0.75 \\
\hline BA(MSWI-B) & $200-400$ & $1100-1300$ & $320(32.5 \mathrm{R}-42.5 \mathrm{R})$ & 0.75 \\
\hline ES(MSWI-B) & $100-200$ & $1300-1400$ & $320(32.5 \mathrm{R}-42.5 \mathrm{R})$ & 0.65 \\
\hline WWTP SLUDGE & 200 & 1800 & $270(32.5 \mathrm{R})$ & \\
\hline
\end{tabular}

* superplasticizer addition $\left(3 \mathrm{~kg} \mathrm{~m}^{-3}\right)$.

As concerns the tests carried out, initially the residues were characterized in order to define their chemical and physical properties according to technical norms for the use of aggregate in concrete production [13-15].

Moreover, the mechanical characterization of concrete mixtures was provided by analysing the compressive [16] and tensile strength [17].

The environmental compatibility was assessed by means of leaching tests, according to UNI EN 12457-2 for granular material [18] and UNI 10802 for concrete mixtures [19]. 


\section{Results and discussion}

\subsection{Characterization of residues}

The chemical composition of the residues analysed is reported in Table 3. Significant concentrations of $\mathrm{Fe}, \mathrm{Ca}, \mathrm{Si}, \mathrm{Al}$ and $\mathrm{Mg}$ were detected in the steel and Waelz slag. As concerns the potential environmental impact, the steel slag showed high concentrations of $\mathrm{Cr}_{\text {tot }}, \mathrm{V}$ and $\mathrm{Ba}$; in the foundry sand and lead slag, $\mathrm{Cu}$ and $\mathrm{Pb}$ were very relevant. Regarding the solid residues of MSWI, the content of metals depends both on the chemical composition of the MSW fed to the incinerator and on their volatility. The washing process was able to reduce the pollutant concentration, with the exception of Fe, $\mathrm{Mn}, \mathrm{Ba}$ and As. The exhausted sand from fluidized bed reactor showed higher content of $\mathrm{Zn}, \mathrm{Cr}_{\text {tot }}$ and $\mathrm{Ni}$ with respect to the bottom ash, probably due to the several recirculation of the sand inside the burning chamber during waste combustion, that increased the concentration of pollutants contained in the sand itself.

Table 3. Chemical composition of residues [7, 20-23]. n.d.: not determined.

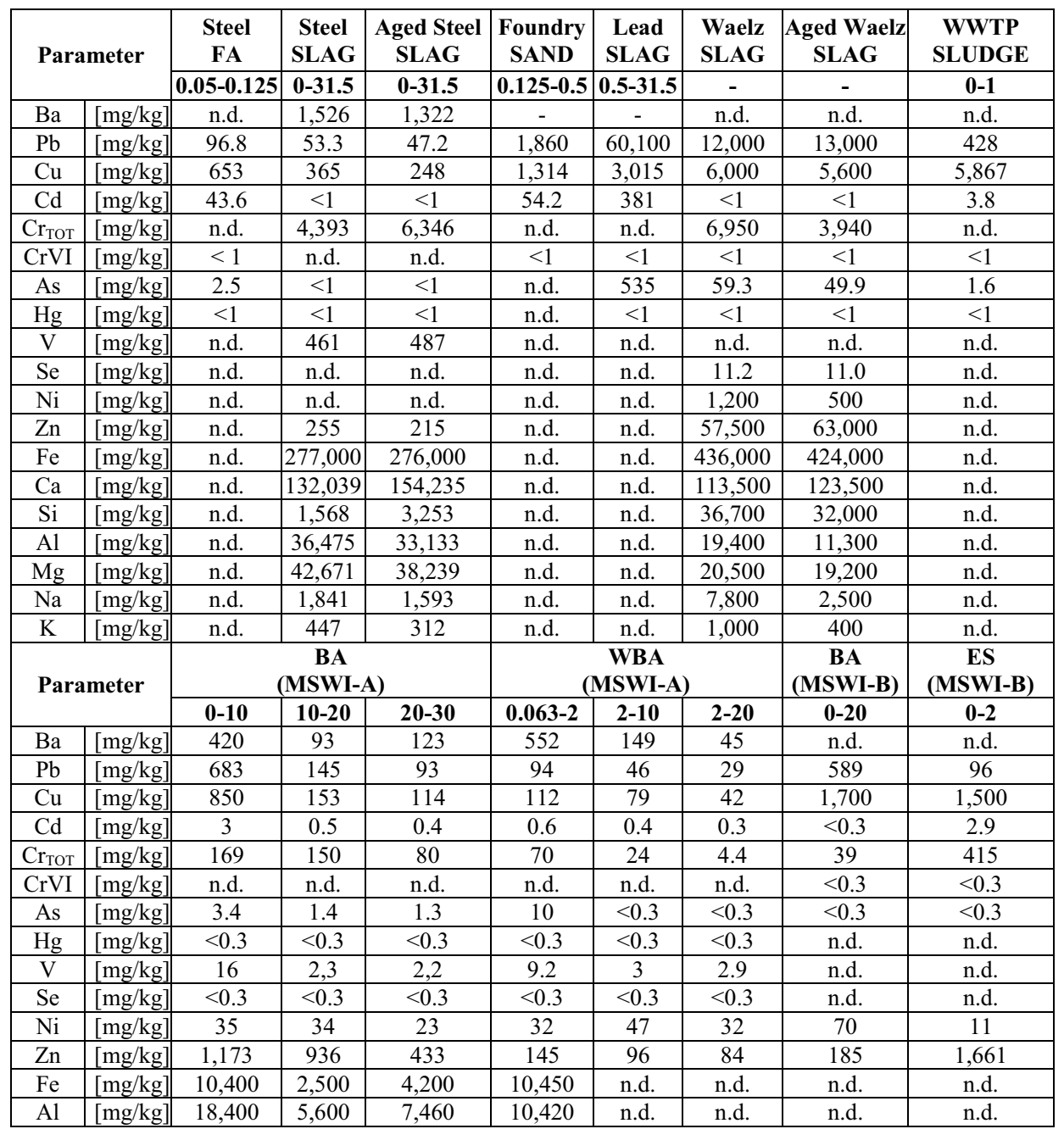

FA: fly ash; BA: bottom ash; WBA: washed bottom ash; ES: exhausted sand. 
According to technical norms [13-15], the aged Steel SLAG and the WBA(MSWI-A) could be used as aggregate for concrete production. The ageing treatment (for 3-4 months) allowed to reduce the volumetric expansion of fresh Steel SLAG and to avoid cracking phenomena in concrete mixtures [7]. Moreover, the washing process applied to bottom ash from MSWI mass-burning kiln was able to reduce the contents of acid-soluble sulphates (that could involve concrete expansion) and water-soluble chlorides [22].

The different particle density (i.e. for steel SLAG much higher than natural aggregates) and water absorption (1-2.5\% for aged Steel SLAG and 1.6\% for WBA(MSWI-A)) should be carefully considered for concrete mix design.

\subsection{Characterization of concrete mixtures}

Regarding the concrete mixtures casted with the residues from metallurgical industry, the results of compressive strengths after 28 days of curing are summarized in Figure 1.

It can be noted that the partial replacement of natural aggregate with lead SLAG, also with a low cement dosage $\left(270 \mathrm{~kg} / \mathrm{m}^{3}\right.$ of CM32.5R or $220 \mathrm{~kg} / \mathrm{m} 3$ of CEM $\left.42.5 \mathrm{R}\right)$, allowed to obtain compressive strengths close to $20 \mathrm{MPa}$. Moreover, the use of aged steel SLAG as complete replacement of natural aggregates led to good mechanical performance [7].

As concerns the Waelz SLAG, the ageing treatment seemed not to be effective in terms of compressive strength enhancement; furthermore, the increase of residue dosage (from 200 to $600 \mathrm{~kg} / \mathrm{m}^{3}$ ) allowed to obtain compressive strengths higher than $35 \mathrm{MPa}$, with the use of CEM 42.5R $\left(300 \mathrm{~kg} / \mathrm{m}^{3}\right)$ [21].

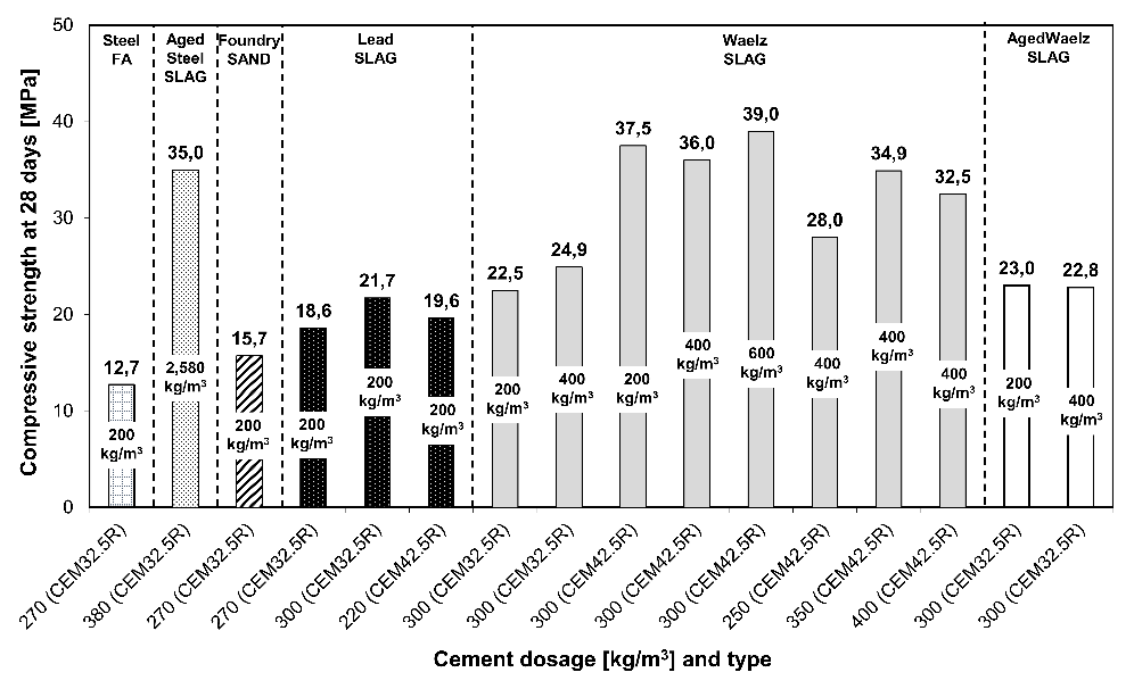

Fig. 1. Compressive strength of concrete mixtures casted with residues from metallurgical industry.

As concerns the residues derived from mass-burning kiln (MSWI-A), the effect of washing was relevant (Figure 2). Using dosages of 400 and $600 \mathrm{~kg} / \mathrm{m}^{3}$, the compressive strength values were higher than $15 \mathrm{MPa}$. Moreover, the use of the CEM42.5R, instead of the CEM32.5R, allowed to obtain an increase of concrete strength and could reduce the concrete swelling [22]. The dosage increase of residues from fluidized bed reactor (MSWIB) led to an enhancement of compressive strength. The results obtained suggested that, although the use of these residues could negatively affect the concrete performance, an increased percentage of bottom ash and exhausted sand could contribute to improve the grading curve towards the achievement of lower porosity [24]. 
Finally, the mixtures casted with sludge as a partial replacement of natural aggregate (200 $\mathrm{kg} / \mathrm{m}^{3}$ only) showed a low compressive strength.

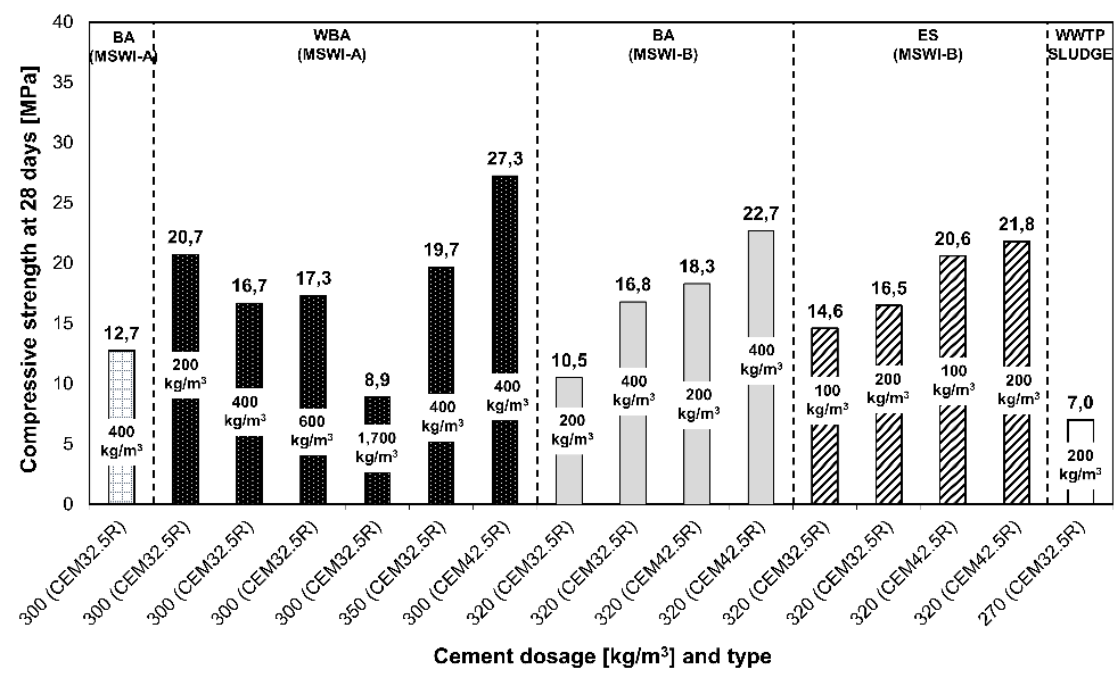

Fig. 2. Compressive strength of concrete mixtures casted with residues from MSWI and sludge.

The results of concrete mixtures mechanical characterization showed that the use of aged steel SLAG and Waelz SLAG do not affect the tensile strength. Furthermore, the dosage of bottom ash from fluidized bed reactor had a negative effect on tensile strength; this phenomena could be significantly reduced with the use of a better quality cement (CEM42.5R instead CEM32.5R).

\subsection{Release of pollutants from residues and concrete mixtures}

The results of the leaching test (according to UNI EN 12457-2) carried out on the steel SLAG and solid residues from MSWI are shown in Table 4.

According to the Ministerial Decree 2006/186 [25], the unwashed BA from mass-burning kiln (MSWI-A) and the residues from fluidized bed reactor (MSWI-B), especially the exhausted SAND, were not suitable for recovery in simplified procedures [23]. This behaviour could be explained, as said above, as a consequence of several recirculation of the sand in the burning kiln during the combustion.

As concerns the BA from fluidized bed reactor, a slight exceeding of total chromium normative limits could be reduced by means of a washing or ageing treatment. In fact, the washing treatment allowed to obtain residues that could be reused according to the simplified procedure. The concentrations of chromium and copper in the leachate obtained from the exhausted sand were higher than both the concentrations measured for the unwashed bottom ashes and the limit values for waste recovery in simplified procedures.

The results of leaching test for the steel SLAG (Table 4) were good: the only parameter that exceeds the limit value was total chromium [21]. As expected, as well as the MSWI residues, the release of pollutants increased in the finest granular fraction due to the higher specific surface.

The environmental compatibility of concrete mixtures, evaluated by means of leaching test for monolithic materials, has shown that the use of $400 \mathrm{~kg} / \mathrm{m}^{3}$ of washed bottom ash for mass-burning kiln and bottom ash from fluidized bed reactor allowed to obtain release of pollutants similar to the reference concrete mixtures (see Table 5). The release increasing in 
the crushed concrete samples was probably due both to the increase of the material specific surface and to the cement that significant content of chromium, barium and sulphate [22].

The leaching tests performed on concrete casted with the use of lead SLAG and Waelz SLAG have not shown any problems in terms of pollutants release [7,21].

Table 4. Results of leaching test for solid residues (the values highlighted are higher than limits) -

UNI EN 12457-2. All results are expressed in $\mathrm{mg} / \mathrm{L}$ with the exception of $\mathrm{pH}$. n.d.: not determined.

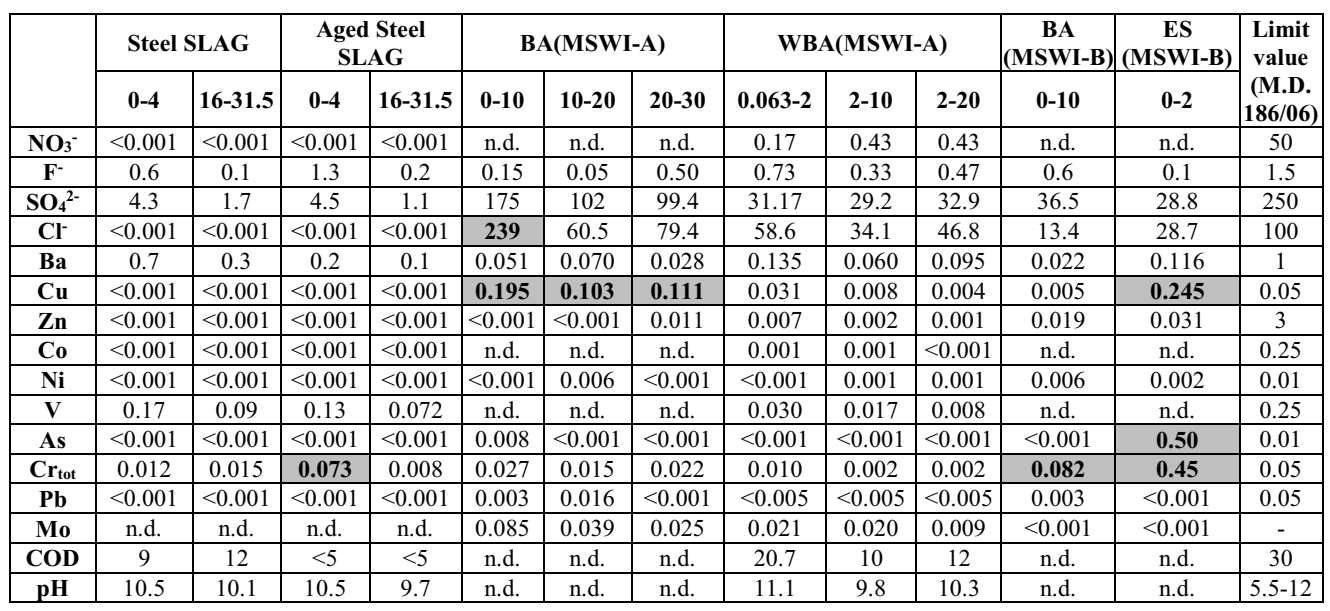

Table 5. Results of leaching test for concrete mixtures. All results are expressed in $\mathrm{mg} / \mathrm{kg}\left(\mathrm{CN}^{-}, \mathrm{As}\right.$, $\mathrm{Be}, \mathrm{Se}, \mathrm{Co}$ and $\mathrm{Hg}$ are lower than instrumental detection limit for all extractions).

\begin{tabular}{|c|c|c|c|c|c|c|c|c|c|c|}
\hline & \multicolumn{2}{|c|}{ Reference mixture } & \multicolumn{2}{|c|}{$\begin{array}{c}\text { WBA(MSWI-A) } \\
400 \mathrm{~kg} / \mathrm{m}^{3}\end{array}$} & \multicolumn{2}{|c|}{ Reference mixture } & \multicolumn{2}{|c|}{\begin{tabular}{|c|} 
BA(MSWI-B) \\
$400 \mathrm{~kg} / \mathrm{m}^{3}$
\end{tabular}} & \multicolumn{2}{|c|}{$\begin{array}{c}\text { ES(MSWI-B) } \\
200 \mathrm{~kg} / \mathrm{m}^{3}\end{array}$} \\
\hline & Monolit. & Granular & Monolit. & Granular & Monolit. & Granular & Monolit. & Granular & Monolit. & Granular \\
\hline $\mathbf{F}^{-}$ & $\begin{array}{l}0.50 \\
\end{array}$ & 8 & 0.75 & 7 & 3.38 & 0.8 & 3.53 & 2.5 & 3.04 & 0.6 \\
\hline $\mathrm{Cl}^{-}$ & 64.9 & 89 & 25.7 & 49 & 28.1 & 70 & 453.8 & 80 & 50.3 & 100 \\
\hline $\mathrm{NO}_{3}^{-}$ & 2.38 & 3 & 1.19 & 3 & 53.3 & 140 & 14.50 & 170 & 3.91 & 100 \\
\hline $\mathrm{SO}_{4}{ }^{2-}$ & 21.8 & 32 & 28.4 & 25 & 114.6 & 1,750 & 223.7 & 2,160 & 198.9 & 1,310 \\
\hline Ba & 0.11 & 1.14 & 0.38 & 5.84 & 0.20 & 6.05 & 0.20 & 5.15 & 0.13 & 5.9 \\
\hline $\mathrm{Cr}_{\text {tot }}$ & 0.04 & 0.17 & $<0.04$ & 0.015 & 0.06 & 0.54 & 0.16 & 0.47 & 0.12 & 0.46 \\
\hline $\mathbf{N i}$ & $<0.04$ & 0.015 & $<0.05$ & 0.01 & 0.01 & $<0.01$ & 0.03 & $<0.01$ & 0.54 & $<0.01$ \\
\hline $\mathbf{P b}$ & $<0.16$ & 0.245 & 0.18 & 0.375 & 0.24 & $<0.01$ & 0.23 & $<0.01$ & 0.21 & $<0.01$ \\
\hline $\mathbf{C u}$ & $<0.07$ & 0.01 & $<0.02$ & 0.015 & 0.07 & 0.11 & 0.08 & 0.16 & 0.05 & 0.14 \\
\hline $\mathbf{Z n}$ & 0.19 & 0.085 & 0.51 & 0.12 & 0.12 & 0.38 & 0.42 & 0.86 & 0.26 & 0.48 \\
\hline Mo & 0.02 & 0.02 & 0.04 & 0.04 & - & - & - & - & - & - \\
\hline COD & $<37.5$ & 45 & $<50$ & 60 & 85.4 & 300 & 79.4 & 800 & 77.8 & 400 \\
\hline
\end{tabular}

Monolit: test carried out on monolithic samples ; Granular : test carried out on granular samples

\section{Conclusions}

The reuse of solid residues derived from metallurgical industry and from MSW incineration as "recycled aggregates" in construction sector could be an interesting alternative to landfill disposal.

An experimental work was carried out on concrete samples casted with different residues in partial replacement of natural aggregates. Mechanical tests were performed to determine the compressive and the tensile strength; leaching tests were also carried out both on granular residues and concrete mixtures.

Good mechanical characteristics are shown for concrete mixtures produced with lead slag, aged steel slag, Waelz slag, washed bottom ash from mass-burning kiln, bottom ash and 
exhausted sand from fluidized bed reactor; on the other hand, concrete samples produced with steel fly ash, foundry sand and WWTP sludge showed worse mechanical characteristics.

The environmental compatibility of steel slag and washed bottom ash was acceptable. Moreover, the leaching test performed on concrete mixtures casted with washed bottom ash from mass-burning kiln, bottom ash and exhausted sand from fluidized bed reactor showed a release of pollutants similar than reference concrete.

The authors wish to thank "PBR s.r.l." (Maclodio, Brescia), "MISE s.r.l." (Tromello, Pavia), "Bosetti s.r.l." (Roè Volciano, Brescia) and "Megazzini s.r.l." (Bressana Bottarone, Pavia) companies and the Laboratory of Department of Civil and Architectural Engineering (University of Pavia) for their collaboration during the experimentation.

\section{References}

1. M. Behera, S.K. Bhattacharyya, A.K. Minocha, R. Deoliya, S. Maiti, Constr. Build. Mater. 68, 16 (2014)

2. M. Calkins, Materials for Sustainable Sites: A Complete Guide to the Evaluation, Selection, and Use of Sustainable Construction Materials (Wiley, New Jersey, 2009)

3. K. Lawania, P. Sarker, W. Biswas, Mater. 8, 17 (2015)

4. Directive 2008/98/EC of the European Parliament and of the Council of 19 November 2008 on waste and repealing. Official Journal of European Union (2008).

5. Ministerial Decree 14 January 2008. Italian law on the Official Gazette 29 (2008)

6. Euroslag, Position Paper on the Status of Ferrous Slag (2012)

7. L. Rondi, G. Bregoli, S. Sorlini, L. Cominoli, C. Collivignarelli, G. Plizzari, Compos. Part B-Eng. 90, 8 (2016)

8. D. Mombelli, C. Mapelli, S. Barella, A. Gruttadauria, U. Di Landro, Process. Saf. Environ. 94, 12 (2015)

9. *** http://life-foundrysand.com/, accessed 8.03.2017

10. Eurostat, http://appsso.eurostat.ec.europa.eu/nui/show.do?dataset=env_wasmun\&lang=en, accessed 8.03.2017

11. Milieu, WRC, RPA, Environmental, economic and social impacts of the use of sewage sludge on land Final Report Part I: Overview Report (2010)

12. M.C. Collivignarelli, A. Abbà, S. Padovani, M. Frascarolo, D. Sciunnach, M. Turconi, M. Orlando, Environ. Eng. Manage. J. 14, 10 (2014)

13. *** UNI EN $12620(2008)$

14. *** UNI $8520-1(2015)$

15. *** UNI 8520-2 (2016)

16. *** UNI EN 12390-3 (2009)

17. *** UNI EN 12390-6 (2010)

18. *** UNI EN $12457-2$ (2004)

19. *** UNI $10802(2013)$

20. S. Sorlini, C. Collivignarelli, Fifth International Conference on the Environmental and Technical Implications of Construction with Alternative Materials, Wascon Conference 2003 (San Sebastian, 2003)

21. S. Sorlini, C. Collivignarelli, G. Plizzari, M. Delle Foglie, Proceedings of the International RILEM Conference on the use of recycled materials in buildings and structures, Barcelona, Spain (2004)

22. S. Sorlini, A. Abbà, C. Collivignarelli, Waste Manage. 31, 9 (2011)

23. M.C. Collivignarelli, A. Abbà, S. Sorlini, M. Bruggi, J. Mater. Cycles Waste Manage. (to be published)

24. A. Abbà, M.C. Collivignarelli, S. Sorlini, M. Bruggi, Compos. Part B-Eng. 58, 8 (2014)

25. Ministerial Decree 5 April 2006 n. 186, Italian law on the Official Gazette 115 (2006) 